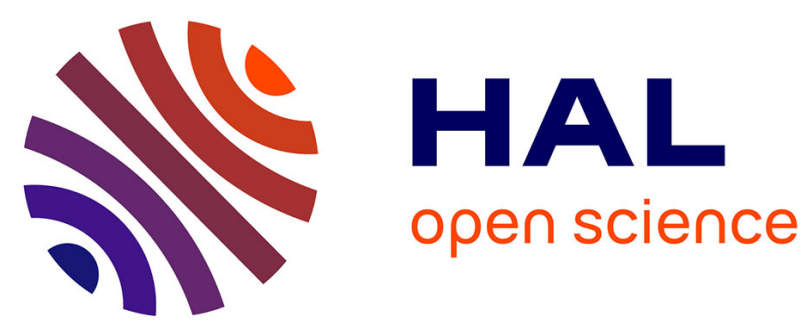

\title{
Kinetic and equilibrium studies of copper-dissolved organic matter complexation in water column of the stratified Krka River estuary (Croatia)
}

Yoann Louis, Cédric Garnier, Véronique Lenoble, Stéphane Mounier, Neven Cukrov, Dario Omanović, Ivanka Pižeta

\section{To cite this version:}

Yoann Louis, Cédric Garnier, Véronique Lenoble, Stéphane Mounier, Neven Cukrov, et al.. Kinetic and equilibrium studies of copper-dissolved organic matter complexation in water column of the stratified Krka River estuary (Croatia). Marine Chemistry, 2009, 114, pp.110-119. 10.1016/j.marchem.2009.04.006 . hal-01096836

\section{HAL Id: hal-01096836 \\ https://hal-univ-tln.archives-ouvertes.fr/hal-01096836}

Submitted on 5 Jan 2015

HAL is a multi-disciplinary open access archive for the deposit and dissemination of scientific research documents, whether they are published or not. The documents may come from teaching and research institutions in France or abroad, or from public or private research centers.
L'archive ouverte pluridisciplinaire HAL, est destinée au dépôt et à la diffusion de documents scientifiques de niveau recherche, publiés ou non, émanant des établissements d'enseignement et de recherche français ou étrangers, des laboratoires publics ou privés. 


\title{
Kinetic and equilibrium studies of copper-dissolved organic matter complexation in water column of the stratified Krka River estuary (Croatia)
}

\author{
Yoann Louis ${ }^{\mathrm{a}, 1}$, Cédric Garnier ${ }^{\mathrm{a}, \mathrm{b}, *}$, Véronique Lenoble $^{\mathrm{a}}$, Stéphane Mounier ${ }^{\mathrm{a}}$, Neven Cukrov ${ }^{\mathrm{c}}$, \\ Dario Omanović ${ }^{c}$, Ivanka Pižeta ${ }^{c}$ \\ a Laboratoire PROTEE, Université du Sud Toulon-Var-BP 20132, 83957 La Garde, France \\ ${ }^{\mathrm{b}}$ Groupe de Physico Toxico Chimie des Systèmes Naturels, Institut des Sciences Moléculaires (ISM-UMR CNRS 5255), Université Bordeaux I, 33405 Talence, France \\ ' Department for Marine and Environmental Research, Ruđer Bošković Institute, P.O. Box 180, 10002 Zagreb, Croatia
}

\section{A R T I C L E I N F O}

\section{Article history:}

Received 6 November 2008

Received in revised form 20 April 2009

Accepted 20 April 2009

Available online 23 April 2009

\section{Keywords:}

Dissolved organic matter

Chemical speciation

Anodic stripping voltammetry

Copper complexing capacity

Kinetics

Estuaries

\begin{abstract}
A B S T R A C T
An interaction of dissolved natural organic matter (DNOM) with copper ions in the water column of the stratified Krka River estuary (Croatia) was studied. The experimental methodology was based on the differential pulse anodic stripping voltammetric (DPASV) determination of labile copper species by titrating the sample using increments of copper additions uniformly distributed on the logarithmic scale. A classical at-equilibrium approach (determination of copper complexing capacity, CuCC) and a kinetic approach (tracing of equilibrium reconstitution) of copper complexation were considered and compared. A model of discrete distribution of organic ligands forming inert copper complexes was applied. For both approaches, a home-written fitting program was used for the determination of apparent stability constants $\left(K_{i}^{\text {equ }}\right)$, total ligands concentration $\left(L_{i T}\right)$ and association/dissociation rate constants $\left(k_{\mathrm{i}}^{1}, k_{\mathrm{i}}^{-1}\right)$.

A non-conservative behaviour of dissolved organic matter (DOC) and total copper concentration in a water column was registered. An enhanced biological activity at the freshwater-seawater interface (FSI) triggered an increase of total copper concentration and total ligand concentration in this water layer. The copper complexation in fresh water of Krka River was characterised by one type of binding ligands, while in most of the estuarine and marine samples two classes of ligands were identified. The distribution of apparent stability constants $\left(\log K_{1}^{\text {equ}}: 11.2-13.0, \log K_{2}^{\text {equ }}: 8.8-10.0\right)$ showed increasing trend towards higher salinities, indicating stronger copper complexation by autochthonous seawater organic matter.

Copper complexation parameters (ligand concentrations and apparent stability constants) obtained by atequilibrium model are in very good accordance with those of kinetic model. Calculated association rate constants $\left(k_{1}^{1}: 6.1-20 \times 10^{3}(\mathrm{M} \mathrm{s})^{-1}, k_{2}^{1}: 1.3-6.3 \times 10^{3}(\mathrm{M} \mathrm{s})^{-1}\right)$ indicate that copper complexation by DNOM takes place relatively slowly. The time needed to achieve a new pseudo-equilibrium induced by an increase of copper concentration (which is common for Krka River estuary during summer period due to the nautical traffic), is estimated to be from 2 to $4 \mathrm{~h}$.

It is found that in such oligotrophic environment (dissolved organic carbon content under $83 \mu \mathrm{M}_{\mathrm{C}}$, i.e. $1 \mathrm{mg}_{\mathrm{C}} \mathrm{L}^{-1}$ ) an increase of the total copper concentration above $12 \mathrm{nM}$ could enhance a free copper concentration exceeding the level considered as potentially toxic for microorganisms (10 pM).
\end{abstract}

(c) 2009 Elsevier B.V. All rights reserved.

\section{Introduction}

It is well known that in aquatic systems the dissolved natural organic matter (DNOM) plays a major role in metals speciation, affecting their bioavailability and toxicity towards micro- and macroorganisms (Buffle, 1988; Bruland and Lohan, 2004; Hirose, 2007; Sunda et al., 1987). Interaction of metals with DNOM depends on the

\footnotetext{
* Corresponding author. Tel.: +33 494142306; fax: +33 494142168. E-mail addresses: louis@univ-tln.fr (Y. Louis),c.garnier@ism.u-bordeaux1.fr (C. Garnier), lenoble@univ-tln.fr (V. Lenoble), mounier@univ-tln.fr (S. Mounier), ncukrov@irb.hr (N. Cukrov), omanovic@irb.hr (D. Omanović), pizeta@irb.hr (I. Pižeta). 1 Tel.: +33494142608.
}

physicochemical conditions of the system: ionic strength, $\mathrm{pH}$, competition with other major and trace cations (Bruland and Lohan, 2004; Lu and Allen, 2002).

Modelling/prediction of trace metal speciation is mainly based on data obtained under conditions which are defined as stationary (assumption of equilibrium). However, dynamic feature of chemical reactions in natural systems leads to non-equilibrium conditions. Systems such as rivers, lakes, estuaries and oceans surface could be under permanent, highly fluctuating physicochemical changes, generating metal speciation far from equilibrium (Hering and Morel, 1989, 1990; Langford and Cook, 1995).

It has been shown that in marine environments kinetics of trace metal complexation can be considerably lowered, mainly because of 
competitive effect with calcium-magnesium cations. Slow dissociation rate of $\mathrm{Ca}-\mathrm{Mg}$ DNOM-complexes and competition with other trace elements are key factors which control degree of trace metal complexation and kinetics of its association with DNOM (Hering and Morel, 1988; Raspor et al., 1980).

Many experimental studies of DNOM-metal interactions do not take account of kinetics (Benedetti, 2006) or assumes fast kinetics (Cheng and Allen, 2006), defining the chemical system at equilibrium. As this equilibrium is a simplification, it could be reasonable to take such data with caution if they are used to predict metal speciation in natural systems using software such as e.g. FITEQL, PHREEQ MINTEQ, MINEQL, CHESS, which assume that system is at equilibrium (Westall et al., 1976; Herbelin and Westall, 1999; Van der Lee and De Windt, 2000; Dudal and Gerard, 2004 and references therein). As a consequence, an overestimation of the metal toxicity could arise. Thus, if reactions are slow, the application of speciation models to natural water systems requires knowledge about kinetics.

There are no available analytical techniques capable to measure "true" non-equilibrium metal speciation in natural systems. A few attempts for in-situ electrochemical measurements are first step in obtaining "real-time" metal speciation in dynamic aquatic environments (Tercier-Waeber et al., 2005 and references therein). Such analyses provide information about operationally defined fraction of trace metals with respect to the applied analytical procedure. Further efforts to develop long-lasting and robust electrochemical sensors with high sensitivity and selectivity to different metal species are needed.

An alternative approach directed to explore dynamic nature of metal speciation is to study kinetics of chemical reactions induced by the addition of metal ions or other complexing ligand. In few papers, ligand exchange kinetics were applied to study the release of metal already bound to DNOM (e.g. Hassan et al., 2008; Fasfous et al., 2004; Langford and Cook, 1995). However, an important aspect in the dynamic metal speciation studies is to predict the kinetics of metal complexation by DNOM excited by the increase of metal concentration. Few studies were performed in order to characterize the kinetics of organic ligands complexation with trace metals using simple ligands such as EDTA and/or extracted humic substances (Ma et al., 1999; Hering and Morel, 1989, 1990), or natural sample but with high dissolved organic carbon (DOC) contents (Achterberg et al., 2002). The outcome of such experiments contributes to the global knowledge of the trace metal behaviour in natural aquatic systems.

Due to low organic carbon content (8-83 $\mu \mathrm{MC}$; Vetter et al., 2007) associated with trace levels of metals (rarely higher than some $\mathrm{nM}$ ), the study of DNOM binding properties in unpolluted systems remains complex, needing convenient analytical techniques usable at very low metal and carbon concentrations. Among all the analytical techniques developed for trace metal analysis and speciation (GFAAS, ICP/MS, ISE, etc.), voltammetric and potentiometric stripping techniques and particularly the differential pulse anodic stripping voltammetry (DPASV) are suitable to apply in natural conditions, especially in a chloride media without any pre-treatments, minimizing possible DNOM structural or physico-chemical modifications (Buffle and Tercier-Waeber, 2005).

The aim of this study is to develop and to explore an analytical procedure and a modelling scheme in order to determine and compare copper-DNOM complexing parameters under assumption of equilibrium conditions and under kinetic regime. For this purpose samples from water column of the non-polluted highly stratified Krka River estuary having low concentrations of metal and organic mater (but with expected seasonal increase of copper concentration) were studied. Dynamics of copper complexation and corresponding speciation scheme initiated by the increased copper concentration were considered.

\section{Experimental}

\subsection{Sampling site and sampling procedure}

The Krka River is a medium sized non-contaminated river of $49 \mathrm{~km}$ of length with an average flow measured over the last 50 years varying between 40 and $60 \mathrm{~m}^{3} \mathrm{~s}^{-1}$ (Bonacci et al., 2006). The Krka River estuary starts below waterfalls (Skradinski buk) and ends at the mouth of the Šibenik channel. Along the estuary total length of $23.5 \mathrm{~km}$, water column is permanently stratified because of a sheltered geography and a low tidal range $(20-50 \mathrm{~cm}$ ). Due to low anthropogenic activities (Cukrov et al., 2008), Krka River and its estuary are oligotrophic (DOC content under $83 \mu \mathrm{MC}$ ), with ultratrace levels of heavy metals (Elbaz-Poulichet et al., 1991). However, during summer the total copper concentration increases, mainly because of nautical traffic (Omanović et al., 2006).

Numerous studies have been performed in the Krka River estuary (e.g. special issue of Marine Chemistry, 1991, volume 32). According to these studies the most dynamic layer in the water column is the freshwater-seawater interface (FSI), on which an accumulation of biologically produced organic matter and associated contaminants (e.g. trace metals) could occur (Žutić and Legović, 1987; Svensen et al., 2006). Unfortunately, only one paper dealing with an interaction of trace metals with NOM has been published up to now (Plavšić et al., 2009), where an overview of the copper complexing capacity in the Krka River estuary was presented, showing that the concentration of ligands forming inert copper complexes remained at the same level as 25 years ago.

Samples for our study were collected on the 20th of April 2007 and 1 year later on the 6th of March 2008 in the Krka River estuary (Croatia, Fig. 1). Four samples in 2007 and four in 2008 were taken on a depth profile near the scientific marine station "Martinska", Ruđer Bošković Institute (Point 2 on the map, GPS coordinates: $43^{\circ} 44^{\prime}$ $07.92 \mathrm{~N}, 15^{\circ} 52^{\prime} 39.61 \mathrm{E}$ ) located in front of Šibenik town. Depth profile samples were taken by scuba-diving in pre-cleaned $1 \mathrm{~L}$ FEP (Fluorinated Ethylene Propylene, Nalgene) bottles. The salinity of samples ranged from 5 to 38 in 2007 and from 13 to 38 in 2008. Two additional samples (denoted as "end-members" of the profiles) were taken in 2008: the first one was sampled in the Krka River (Point 1 on the map, GPS coordinates: $43^{\circ} 48^{\prime} 12.42 \mathrm{~N}, 15^{\circ} 58^{\prime} 18.48 \mathrm{E}$ ) and represents fresh water which inflows into the estuary and the second one was taken in the sea (Point 3 on the map, GPS coordinates: $43^{\circ} 42^{\prime}$ $44,88 \mathrm{~N}, 15^{\circ} 47^{\prime} 43,98 \mathrm{E}$ ) out of the estuary direct influence. Both samples were collected at $0.2 \mathrm{~m}$ depth in 1 L FEP bottles (Nalgene). Data points for these two end-member samples are marked in the figures by individual symbols (at depth 0 and $-8.5 \mathrm{~m}$ ). All samples were filtrated on-site through $0.45 \mu \mathrm{m}$ pre-cleaned cellulose nitrate filter (Sartorius) and stored in pre-cleaned $500 \mathrm{~mL}$ FEP or PFA bottles (PerFluoroAlkoxy, Nalgene) at $4{ }^{\circ} \mathrm{C}$ in the dark until analysis (for voltammetric experiments). Samples for DOC measurements were stored in glass tubes (Shimadzu), which are combusted in an oven (Herrmann Moritz, Four MF4) at $450{ }^{\circ} \mathrm{C}$ during $4 \mathrm{~h}$ to remove carbon.

\subsection{Chemicals and instrumentation}

All the vessels used were cleaned with $10 \%$ nitric acid (Fisher Scientific, analytical grade) and rinsed with ultra-pure water (Millipore Milli-Q system). Copper solutions (10,100 and $1000 \mu \mathrm{M})$ used for titration were prepared from AAS copper standard $\left(1 \mathrm{~g} \mathrm{~L}^{-1}\right.$, Fluka). Acidification of samples, when needed, was performed using $65 \%$ $\mathrm{HNO}_{3}$ (Merck, Suprapur).

Concentrations of DOC were determined using a TOC-V analyser (Shimadzu), calibrated using sodium hydrogenophtalate standard solutions, with an accuracy of $0.8 \mu \mathrm{M}_{\mathrm{C}}$.

All voltammetric measurements were carried out with voltammetric analyser PSTAT10 or PGSTAT12 (EcoChemie, Utrecht, The Netherlands) controlled by GPES 4.9 software (Eco Chemie) coupled with the three electrodes system of 663VA Stand (Metrohm, Swiss). The working 


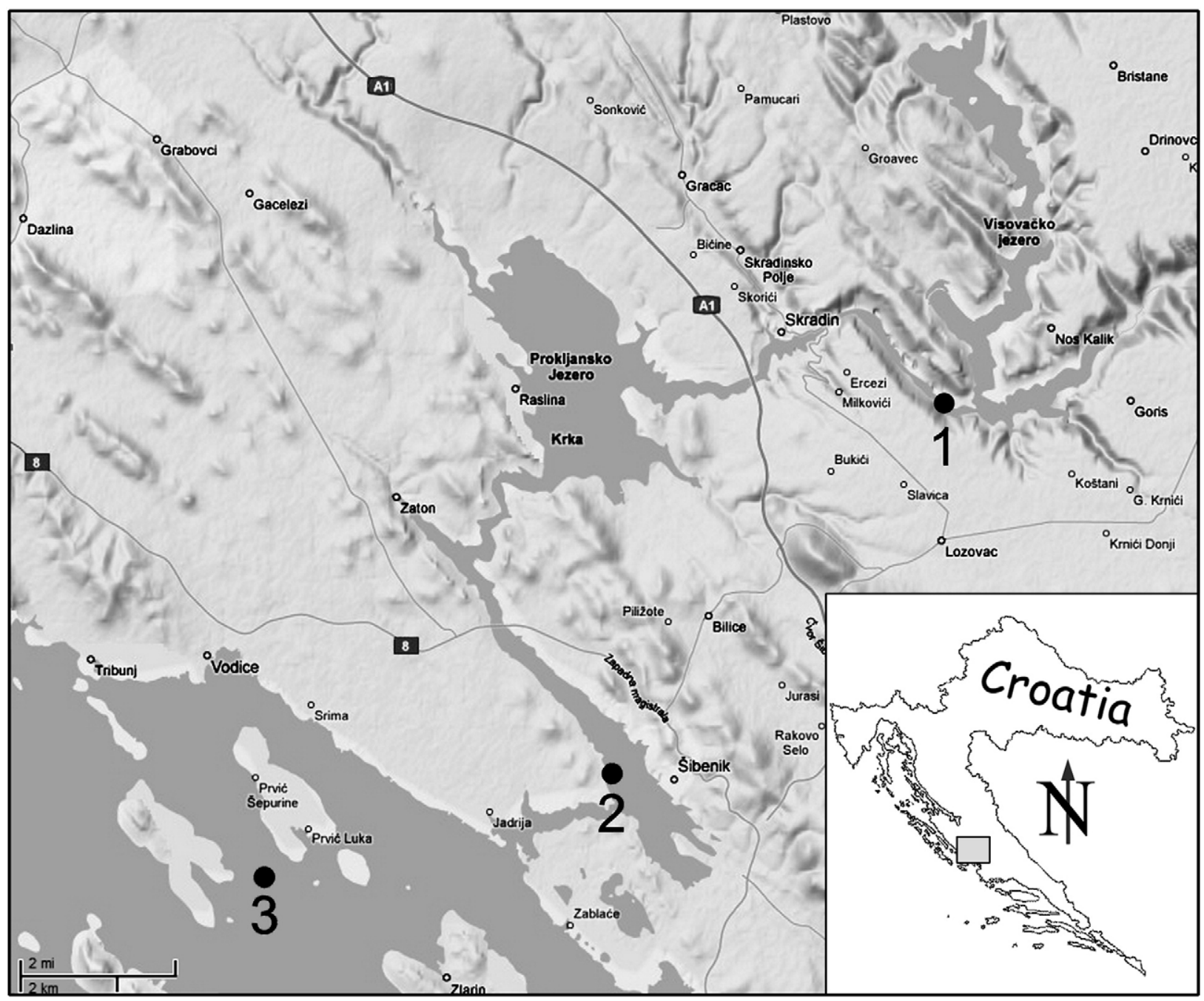

Fig. 1. Locations of sampling sites: 1-Freshwater sample of Krka River, 2-Depth profile samples (Krka River estuary), 3-Seawater sample.

electrode was a static mercury drop electrode (SMDE) ( of area), while a platinum wire was used as a counter electrode. Potentials were given $v$ s. $\mathrm{Ag} \mid \mathrm{AgCl}$ (sat. $\mathrm{KCl}$ ) reference electrode. $20 \mathrm{ml}$ of a sample, supported in a PFA electrochemical cell (Metrohm), was stirred with a Teflon rotating stirrer at $3000 \mathrm{rpm}$. Dissolved oxygen was removed from the solution prior to analysis by purging with ultra-pure nitrogen for at least $15 \mathrm{~min}$. To exclude evaporation of the sample, a water-saturated nitrogen blanket was maintained above the solution surface during the whole experiment. All experiments were performed at room temperature $\left(24 \pm 2{ }^{\circ} \mathrm{C}\right)$. $\mathrm{pH}$ was controlled by a $\mathrm{pH}$ meter (Metrohm, 713 PHM) with a combined pH-micro-electrode (Mettler, Inlab422, reference electrode: $\mathrm{Ag}|\mathrm{AgCl}| \mathrm{KCl} 3.0 \mathrm{M}$ ). Initial $\mathrm{pH}$ values in all analysed samples were between 7.9 and 8.1. During the titration, $\mathrm{pH}$ increased from 0.3 up to 0.5 unity of $\mathrm{pH}$ because of partial removal of carbonates from the solution $\left(\mathrm{CO}_{2}\right.$ degassing). Copper speciation is thus partly changed in the cell-solution during titration, however according to simulation using VisualMINTEQ a change of copper portion associated with strong organic ligands at the ambient conditions in the water column is negligible. Finally, the used method (DPASV) determines conditional complexation parameters (dependent on the applied procedure), and non-ideal conditions are common for such a type of study. For the speciation calculation, a pH value of 8.5 was defined for all the samples. Three automatic burettes (Cavro XE 1000 syringe pumps, Tecan, Swiss) were used to automate copper titration.

The conditions used for DPASV measurements of electro-labile copper were already presented (see Louis et al., 2008). The important point is the deposition time which is divided in two parts: (i) $297 \mathrm{~s}$ at a deposition potential $\left(E_{\mathrm{dep}}\right)$ of $-0.5 \mathrm{~V}$ and (ii) $3 \mathrm{~s}$ at a deposition potential of $-1.6 \mathrm{~V}$. This strong negative potential allows the removal of surface active substances which may adsorb at the electrode surface, producing artefacts on copper stripping peak and inaccuracy on the determination of DNOM/Cu binding parameters (Louis et al., 2008). The other parameters used are a pulse amplitude of $25 \mathrm{mV}$, a potential step increment of $2.5 \mathrm{mV}$, a time between pulses of $0.1 \mathrm{~s}$ with a pulse duration of $0.05 \mathrm{~s}$. The potential was scanned from $-0.6 \mathrm{~V}$ to $0.05 \mathrm{~V}$ or to $0.2 \mathrm{~V}$ depending on the sample salinity.

Total dissolved copper concentrations $\left(\mathrm{Cu}_{\mathrm{T}}\right)$ were determined in acidified and UV-digested sample ( $3 \mathrm{~h}$ on the Metrohm 705 UV Digester, or $12 \mathrm{~h}$ under $150 \mathrm{~W} \mathrm{Hg} \mathrm{lamp)} \mathrm{by} \mathrm{a} \mathrm{standard} \mathrm{addition}$ method (duplicate DPASV measurements on the unspiked sample followed by four or five additions of standard Cu solution) (Capodaglio et al., 1995; Omanović et al., 2006). Detection limit for copper under applied experimental conditions was estimated to $2 \times 10^{-10} \mathrm{M}$.

\subsection{Experiment design and modelling}

$20 \mathrm{ml}$ of each sample was titrated with copper, covering concentration range from $0.5 \mathrm{nM}$ to about $800 \mathrm{nM}$. A titration with copper additions with consistently distributed concentrations along the logarithmic scale (Garnier et al., 2004b) was applied (similar increments in $\log [\mathrm{Cu}]_{\mathrm{T}}$ ). After each copper addition, DPASV measurements were repeated each 6 min (corresponding to the minimal time 
needed to perform an analysis) using the above described procedure. In this way 20 voltammograms per addition, representing the labile part of copper, were obtained within $2 \mathrm{~h}$. These repetitive voltammograms were used in the kinetic study (Fig. 2B). After these $2 \mathrm{~h}$, two additional voltammograms were recorded, which were used for the at-equilibrium analysis (Fig. 2A). For each sample, at least 12 copper additions were performed to accomplish titration.

Peak area was chosen as a characteristic signal value and further used for the calculation of labile copper concentrations according to the sensitivity obtained at the end of the titration curve (measured peak area vs. added total $\mathrm{Cu}$ concentrations). This linear part of the titration curve corresponds to copper concentrations at which ligands active sites responsible for copper complexation are nearly saturated. At least four end-points were used for the sensitivity calculation.

\subsubsection{At-equilibrium approach}

Classical way to characterize DNOM reactivity toward metals consists in applying a conceptual model, which could be either a discrete (Lenoble et al., 2008; Sposito, 1981; Tipping et al., 1998; Town and Filella, 2000) or a continuous (Benedetti, 2006; Dzombak et al., 1986; Kinniburgh et al., 1996) distribution of binding sites. Fitting of the obtained experimental data could be performed using linear (Muller et al., 2001; Ružić, 1982; Scatchard, 1949) or non-linear methods (Dudal and Gerard, 2004 and references therein; Huber et al., 2002; Lu and Allen, 2002).

According to DNOM structural heterogeneity, mono- and multidentate ligands could be expected (Tipping et al., 1998). However, it has been shown in a theoretical study that the corresponding binding parameters are often inaccurately determined (Garnier et al., 2005) due to experimental and fitting uncertainties. Therefore in this study, DNOM binding properties towards copper were modelled using a discrete distribution of mono-dentate binding ligands $\left(L_{i}\right)$, each defined by 2 parameters: a total site concentration $\left(L_{i T}\right)$ and a conditional stability constant $\left(K_{\mathrm{i}}^{\text {equ }}\right)$ (Garnier et al., 2004a; Sposito, 1981).

Association between copper and a mono-dentate ligand $\left(L_{i}\right)$ could be described by the following equation:

$\mathrm{Cu}^{2+}+L_{i} \stackrel{K_{i}^{\text {equ }}}{\Leftrightarrow} \mathrm{CuL}_{i}^{2+}$ with $K_{i}^{\text {equ }}=\frac{\left[\mathrm{CuL}_{i}^{2+}\right]}{\left[\mathrm{Cu}^{2+}\right] \times\left[L_{i}\right]}$

where $\left[\mathrm{Cu}^{2+}\right]$ and $\left[L_{i}\right]$ are free copper and $i$-th ligand concentration, respectively.
In this study, the DNOM reactivity was only described by interactions toward $\mathrm{Cu}^{2+}$. Indeed, the characterisation of DNOM interactions with competition cations such as $\mathrm{H}^{+}$or $\mathrm{Ca}^{2+}$ necessitates additional experiments, after numerous and time consuming DNOM concentration/purification steps (e.g. Louis et al., 2009) which is not the object of this study. So, the mass balance for the i-th ligand is restricted to the equation:

$\left\lfloor L_{i T}\right\rfloor=\left\lfloor L_{i}\right\rfloor+\left\lfloor C u L_{i}^{2+}\right\rfloor$

DPASV measurement leads to the determination of the electrolabile $\mathrm{Cu}$ fraction $\left([\mathrm{Cu}]_{\text {labile }}\right)$, which mostly corresponds to inorganic copper complexes, while a difference between a total $\left(\mathrm{Cu}_{\mathrm{T}}\right)$ and a labile $\mathrm{Cu}$ fraction corresponds to organic complexes ( $\left.\sum\left[\mathrm{CuL}_{\mathrm{i}}^{2+}\right]\right)$, nonlabile under the chosen voltammetric parameter conditions. The relation between free and labile copper concentrations could be expressed as:

$[\mathrm{Cu}]^{2+}=\alpha[\mathrm{Cu}]_{\text {labile }}$

where $\alpha$ is the side reaction coefficient.

Inorganic chemical composition of solution and $\mathrm{pH}$ was taken into account to calculate the inorganic speciation of copper, and so the $\alpha$ value for each experimental data point, using thermodynamic stability constants from MINEQL and MINTEQ databases.

For each sample, determination of the at-equilibrium complexing parameters $\left(L_{i T}, K_{i}^{\text {equ }}\right)$ was performed by fitting a measured set of electro-labile copper concentrations, using the software PROSECE (Garnier et al., 2004b). An example of experimental data set and fitting curve is shown in Fig. 2A. Data are fitted using 1- and 2-ligands models and the one leading to a statistically better fit is chosen. A validation of data fitting procedure was elaborated in details by Garnier et al. (2004b). Although the physico-chemical structure of these one or two classes of natural ligands is unknown, their presumption is often sufficient to correctly describe the DNOMmetal properties in the natural environment (Town and Filella, 2000).

For each of the optimised binding parameters, a confidence interval value is calculated by PROSECE as the maximal absolute variation (in percentage) of the parameter value corresponding to a $10 \%$ increase of the fitting error (sum of the difference between measured and calculated concentrations expressed in log) (Louis et al., 2009).

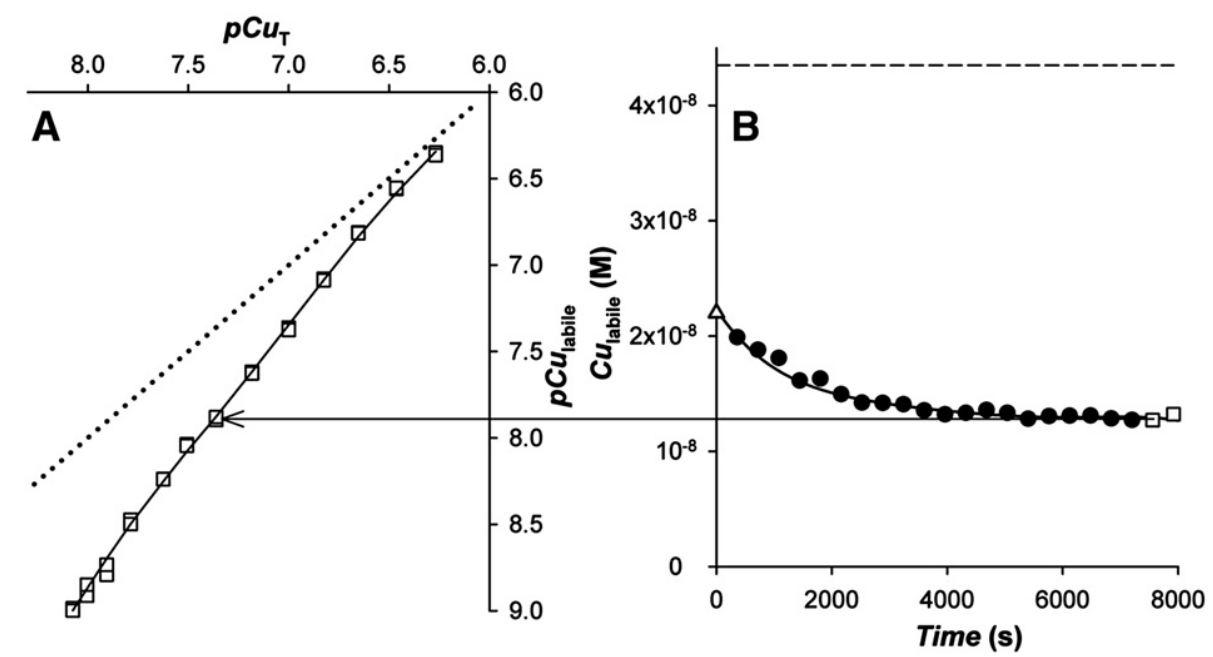

Fig. 2. Sample of salinity 13 (2008) titrated with copper in logarithmic increments. (A)-at-equilibrium obtained experimental points ( $\square$ ), dotted line: non-complexing line, full line: fitting curve. (B)-fitting of the kinetic experimental data ( $)$ for the copper concentration indicated on the plot (A), dashed line: total metal, full line: fitting curve, $\square$-data used for at-equilibrium fitting, $\triangle$-estimated $\mathrm{Cu}_{\text {labile }}$ value at $0 \mathrm{~s}$ of equilibration time. 


\subsubsection{Kinetic approach}

Interaction between copper and a mono-dentate ligand $\left(L_{i}\right)$ could be described by the following pseudo-first order reaction:

$\mathrm{Cu}^{2+}+L_{i} \underset{k_{i}^{-1}}{\stackrel{k_{i}^{1}}{\Leftrightarrow}} \mathrm{CuL}_{i}^{2+}$ with $\frac{k_{i}^{1}}{k_{i}^{-1}}=K_{i}^{\mathrm{equ}}$

where $k_{i}^{1}\left((\mathrm{Ms})^{-1}\right)$ and $k_{i}^{-1}\left(\mathrm{~s}^{-1}\right)$ are the association and dissociation rate constants, respectively.

Association/dissociation rates for inorganic copper complexes are known to be high, and so the corresponding reactions are supposed to be at-equilibrium (Buffle, 1988). The rate of concentration change after addition of copper(II) ions for $i$ organic ligands can be described by:

$\frac{d C u^{2+}}{d t}=\sum_{i}\left(-k_{i}^{1}\left[C u^{2+}\right]\left[L_{i}\right]+k_{i}^{-1}\left[C u L_{i}^{2+}\right]\right)$

For each sample, the $\alpha$ value is determined from the results of the PROSECE fitting of the at-equilibrium titration measurements. Using Eq. (3), the Eq. (5) could be rearranged, and for one organic ligand it reads:

$\frac{d C u_{\text {labile }}}{d t}=-k_{1}^{1}\left[C u_{\text {labile }}\right]\left(\left[L_{1}\right]_{T}-\left(\left[C u_{T}-\left[C u_{\text {labile }}\right]\right)\right)+\frac{k_{1}^{-1}\left([C u]_{T}-\left[C u_{\text {labile }}\right]\right)}{\alpha}\right.$

and for two organic ligands:

$\frac{d C u_{\text {labile }}}{d t}=\frac{1}{\alpha}\left(\begin{array}{l}\alpha\left[C u_{\text {labile }}\right]\left(-k_{1}^{1}\left[L_{1}\right]_{T}-k_{2}^{1}\left[L_{2}\right]_{T}\right)+\left([C u]_{T}-\left[C u_{\text {labile }}\right)\left(\frac{k_{2}^{1}}{k_{2}^{\text {equ }}}+\alpha k_{2}^{1}\left[C u_{\text {labile }}\right]\right)\right. \\ +\left(\frac{K_{1}^{\text {equ }} \alpha\left[C u_{\text {labile }}\right]\left[L_{1}\right]_{T}}{1+K_{1}^{\text {equ }} \alpha\left[C u_{\text {labile }}\right.}\right)\left(\left(k_{1}^{1}-k_{2}^{1}\right)\left[C u_{\text {labile }} \alpha+\left(\frac{k_{1}^{1}}{K_{1}^{\text {equ }}}-\frac{k_{2}^{1}}{K_{2}^{\text {equ }}}\right)\right)\right.\end{array}\right)$

For one set of kinetic binding parameters values $\left(L_{i T}, k_{i}^{1}\right.$ and $\left.k_{i}^{-1}\right)$, calculation of $\mathrm{Cu}_{\text {labile }}$ for each equilibration time is carried out by numerical integration of functions (6) or (7). This integration implies the definition of an additional parameter, $\mathrm{Cu}_{\text {labile }}$ concentration at $0 \mathrm{~s}$ of equilibration time (Fig. 2B, open triangle). This "initial" labile copper concentration could be estimated either numerically (sum of the equilibrated $\mathrm{Cu}_{\text {labile }}$ concentration from the previous addition and the added $\mathrm{Cu}$ ) or graphically (initial trend of the curve $\left[\mathrm{Cu}_{\text {labile }}\right]$ vs. time). As this parameter could have considerable impact on the obtained results, its accurate estimation is of essential importance.

Modifying the PROSECE algorithm (Garnier et al., 2004b), a new program (available on request) devoted for the kinetic data fitting has been written. Calculation algorithms were written using a platform of the numerical calculation program Octave (freeware). The fitting code consisted in an integration subroutine (LSODE function) coupled to an optimisation loop. Experimental data (i.e. the measured $\mathrm{Cu}_{\text {labile }}$ concentrations $v s$. equilibration time after $\mathrm{Cu}$ addition to a sample) were fitted using 1- or 2-ligands model, with the number of ligands determined by at-equilibrium approach. For each addition, the optimal set of binding parameters was obtained, from which the average value and a standard deviation were calculated. An example of data set and fitting curve is shown in Fig. 2B.

\section{Results and discussions}

\subsection{Salinity, DOC and copper depth profiles}

The salinity (Fig. 3A), the dissolved organic carbon (Fig. 3B) and the total dissolved copper concentration (Fig. $3 \mathrm{C}$ ) profiles showed the same trend of vertical distribution between the two sampling campaigns (in 2007 and in 2008) (Table 1). All three profiles indicate a well stratified water column with three different regions: (i) an upper brackish layer, (ii) a thin Freshwater / Seawater Interface (FSI) layer (thickness less than $50 \mathrm{~cm}$ ) at a depth of about $1.5 \mathrm{~m}$ where the salinity sharply increases and (iii) the bottom seawater layer.

The main difference which can be observed between 2007 and 2008 is a higher salinity of brackish surface layer in 2008 with a measured value of 13 , compared to only 5 in 2007 (Fig. 3A). This difference could be explained by a lower river flow for the period of sampling in $2008\left(\sim 22 \mathrm{~m}^{3} \mathrm{~s}^{-1}\right.$ comparing to $\sim 37 \mathrm{~m}^{3} \mathrm{~s}^{-1}$ in 2007), favoured by stronger wind which caused enhanced mixing of layers. In 2007, an enhanced biological activity at the surface water layer has been visually observed, not noticeable in 2008 .

It can be observed that in the freshwater sample, the measured DOC concentration $\left(43.2 \pm 0.9 \mu \mathrm{M}_{\mathrm{C}}\right)$ was half of the concentration found in the seawater sample $\left(80.0 \pm 1.7 \mu \mathrm{M}_{\mathrm{C}}\right)$. This characteristic has already been observed (Cauwet, 1991) for this river, showing that it is a very clean system, submitted to very low anthropogenic inputs.

DOC observed variations according to salinity followed a parabolic trend (full line, inset Fig. 3B) and not the dilution line of a conservative mechanism (short dash, inset Fig. 3B). It means that in the estuarine

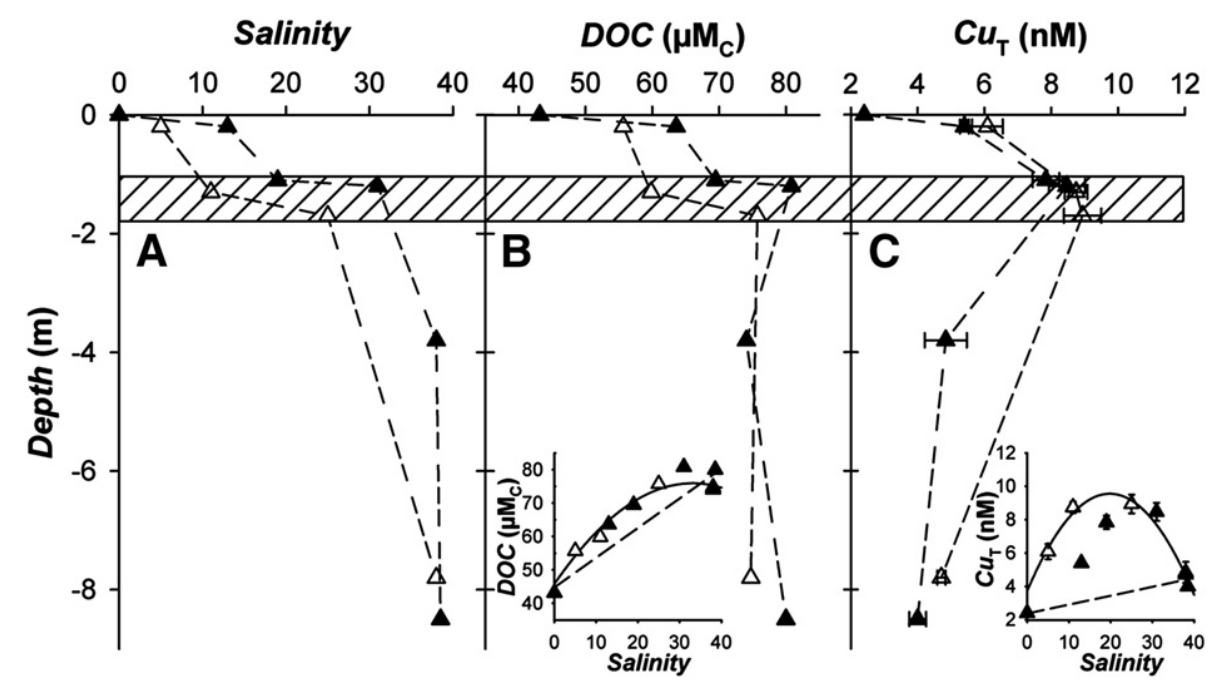

Fig. 3. Salinity (A), DOC (B) and total dissolved copper (C) depth profiles of samples taken in $2007(\triangle)$ and in 2008 ( $\mathbf{\Delta}$ ); marked area represents the depth range where FSI layer occurred for both 2007 and 2008 sampling events. Insets: Same parameters in relation to salinity; Full and dashed lines represent parabolic and conservative variations of DOC (B) and total dissolved copper (C), respectively. 


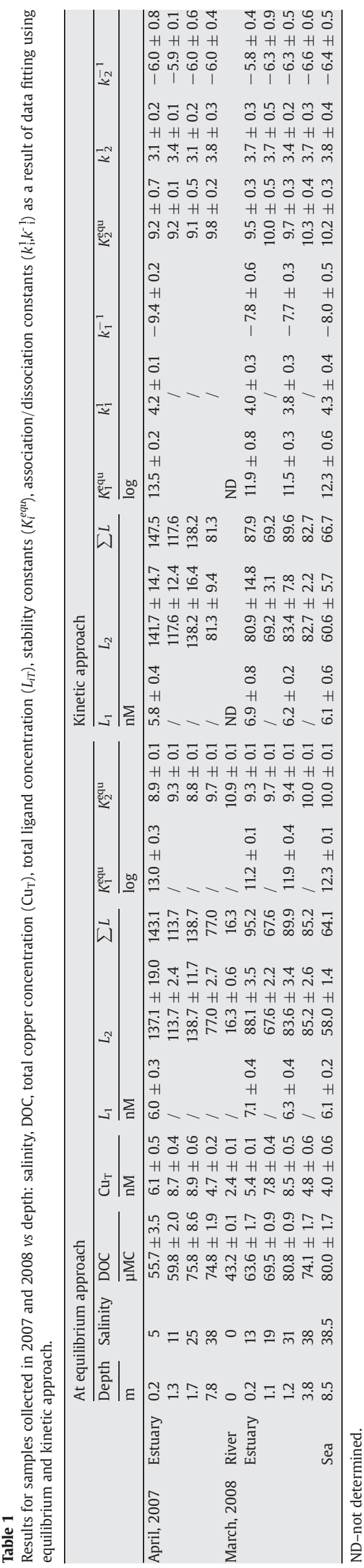

mixing zone, there was an additional source of carbon. Ahel et al. (1996) have already observed in this same estuary an enhanced biological activity in the FSI layer. Knowing that the major part of the DNOM in the aquatic environment is due to degradation or exudation from living organisms (Buffle, 1988), this exacerbated biological activity can explain the higher amount of dissolved organic carbon found in this layer.

Concerning total dissolved copper concentrations, it can be underlined that in the freshwater sample taken in the Krka River, measured concentration is very low, about $2.4 \pm 0.1 \mathrm{nM}$. Comparison of this value with the one measured 20 years earlier $(1.78 \mathrm{nM})$ in the same river (Elbaz-Poulichet et al., 1991) shows that the Krka River maintains very low concentrations of trace metals owing to the efficient mechanism of self-purification (Cukrov et al., 2008) and the absence of significant anthropogenic sources. The observed variations of total $\mathrm{Cu}$ concentrations with salinity also followed a parabolic trend (full line, inset Fig. 3C). Such increase of metal concentration in the FSI layer has already been described for a vertical profile of this (ElbazPoulichet et al., 1991) and other estuaries (Baeyens et al., 1997; Waeles et al., 2004, 2005), and is attributed to a particulate/dissolved metal exchange. When riverine particular organic matter negatively charged reaches the FSI, its ionic charge becomes neutral, due to major cations adsorption, leading to particles coagulation. These cations compete with trace metals initially bound at the particle surface, leading to metal release into the dissolved phase.

\subsection{Copper-dissolved organic matter complexing parameters}

In Fig. $4 \mathrm{~A}$ and $\mathrm{B}$, the depth profiles of ligand concentrations and apparent stability constants calculated with at-equilibrium approach are presented, respectively. All the obtained values are gathered in Table 1.

The river end-member sample was described by only one ligand with a low concentration $(16.3 \pm 0.6 \mathrm{nM})$ associated with a quite high stability constant ( $\log K^{\mathrm{equ}}=10.9 \pm 0.1$ ), ascribed to the class of strong ligands $\left(L_{1}\right)$. This high apparent stability constant is expected to decrease from the river to the sea, due to the increase of major divalent cations competition effect. So, reaching the estuarine zone, this "riverine ligand" will have a decreasing affinity toward copper to the order of magnitude of this of the weaker class of ligands $\left(L_{2}\right)$ found in the estuarine samples. This effect was described by Hamilton-Taylor et al. (2002), studying copper speciation in estuarine conditions for a humic acid.

The sea end-member sample is characterized by 2 ligands $\left(L_{1}\right.$ and $\left.L_{2}\right)$, with lower concentrations $(6.1 \pm 0.2$ and $58.0 \pm 1.4 \mathrm{nM}$, respectively) and higher stability constants $(12.3 \pm 0.1$ and $10.0 \pm 0.1$, respectively) compared to other samples of the estuary profile. Differences of the two end-member samples characteristics could partly be linked to different DNOM sources: terrigeneous in the river, and autochthonous in the seawater. This hypothesis could be supported by the DOC increase observed along the salinity gradient, linked to an in-situ DNOM production, probably by biota known to produce strong ligands (McKnight and Morel, 1979; Coale and Bruland, 1988).

In case of conservative water mixing, it is expected that the ligands concentrations should also be conservative. However, the same is not expected for copper stability constants which are salinity dependent, as explained before. Shank et al. (2004) observed a conservative trend of ligand concentration in the organic-rich Cape Fear estuary, where terrigeneous humic substances are the principal source of DNOM due to high river flow associated to low biological activity. In the Krka River estuary, for both campaigns, non-conservative behaviour was observed for ligands concentrations (Fig. 4A, solid line). The same is valid when observing the site densities (ratios of ligand to DOC concentrations) for the 2008 results: from $31 \mu \mathrm{eq} \mathrm{g}_{\mathrm{C}}^{-1}$ in the river, reaching $115 \mu \mathrm{eq} \mathrm{g}_{\mathrm{C}}^{-1}$ at the surface of the estuary, decreasing to 


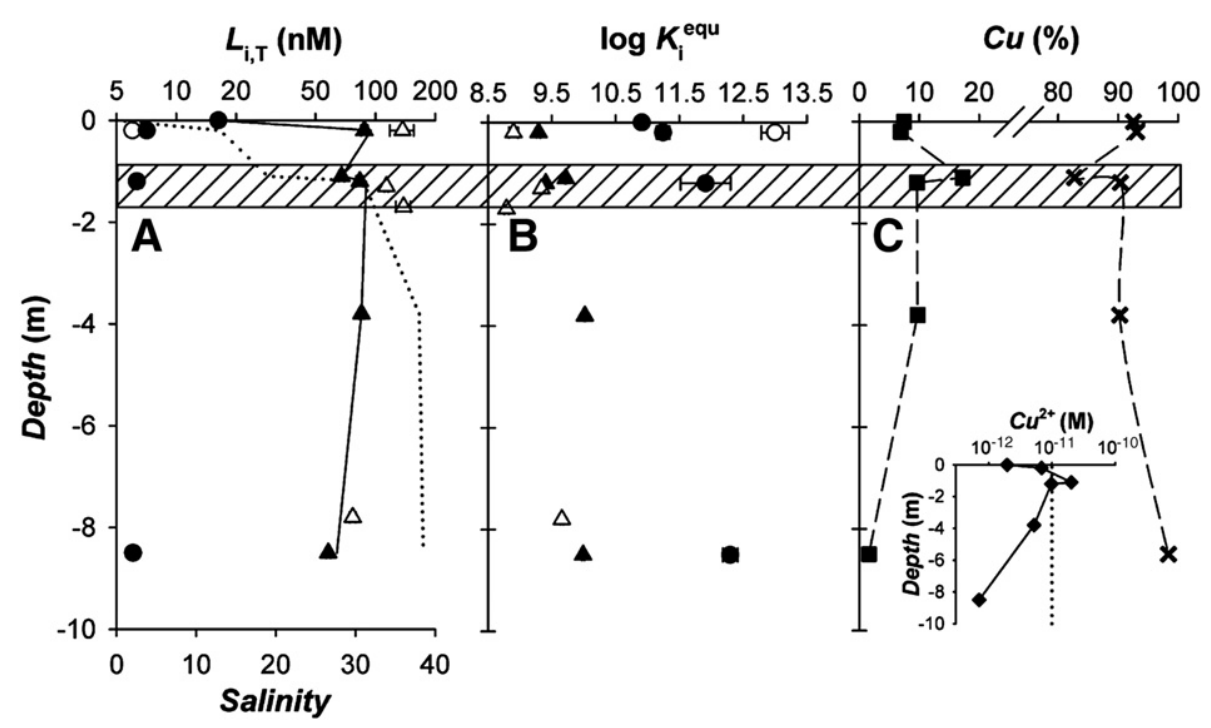

Fig. 4. Ligand concentrations (A) and stability constants (B) as a function of depth for strong $(\odot, \bullet)$ and weak $(\triangle, \mathbf{\Delta})$ ligands for samples taken in $2007(\odot, \triangle)$ and in $2008(\bullet, \mathbf{\Lambda})$. Dotted line: salinity profile for 2008; full line: sum of total ligand concentrations for 2008. (C)-Calculated inorganic ( $\mathbf{\square})$ and organic (X) copper fractions according to depth profile for samples from 2008. Inset: free copper concentration ( ) and the toxicity limit of 10 pM (according to Sunda et al., 1987) represented by dotted line. Marked area represents the depth range where FSI layer occurred for both 2007 and 2008 sampling events.

$80 \mu \mathrm{eq} \mathrm{g}_{\mathrm{C}}^{-1}$ in the FSI and to $60 \mu \mathrm{eq} \mathrm{g}_{\mathrm{C}}^{-1}$ in the seawater layer. Decreasing ligand concentrations from the FSI to the sea water layer was already observed in the Narragansett Bay by Wells et al. (1998).

The stability constants values obtained in this study increased from the estuary surface to the bottom (Fig. 4B), implying stronger ligands in the seawater layer. It could be explained by a production of autochthonous organic matter, originating from the biological activity (Fig. 3B).

The at-equilibrium binding parameters determined for the 2008 samples were incorporated in the speciation program MINEQL to calculate copper speciation with respect to salinity and total copper concentration depth profiles. The obtained depth profile for the organic copper fraction (Fig. 4C) showed a minimum in the FSI layer in spite of the strong increase of total copper concentration and the increase (respectively decrease) of weak (respectively strong) ligand concentration. The inorganic copper fraction increased in the FSI layer leading to free copper concentration (in inset, Fig. 4C) as high as $20 \mathrm{pM}$, two times higher than the toxicity limit for marine phytoplankton defined by Sunda et al. (1987) (dotted line in inset of Fig. 4C). The same tendency was observed for the 2007 samples (data not shown), even stronger as the calculated free copper concentration reached $77 \mathrm{pM}$ in the FSI.

Calculated total ligand concentrations were in positive correlation with the measured total copper concentrations (data not shown). So, the complexing properties of the DNOM present in the estuary seemed to be in a great extent controlled by the autochthonous DNOM produced at the estuary surface, probably by biological activity (Svensen et al., 2006). Despite a higher density of binding sites, these additional ligands were not sufficient to completely buffer the increase of dissolved copper in the FSI, probably coming from particles release.

It could be reasonable to assume that at the FSI layer an exchange of the copper complexation ligands type occurs: from riverine ligands to marine ligands. It was recently showed by Wang and Chakrabarti (2008) that attainment of the copper complexation equilibrium with spiked EDTA in model solution of SRFA and HA took at least overnight $(12 \mathrm{~h})$. Accordingly, the copper complexation properties determined for the samples taken at the FSI and taking into account ligands exchange, could be considered as transitional, representing a dynamic exchange conditions in this layer.
In order to determine the complexing parameters, experimental curves obtained with kinetic approach as the one shown in Fig. 2B were fitted by discrete models as explained in Section 2.3.2. Average binding parameters $\left(\overline{L_{i T}}\right.$ and $\left.\log \overline{K_{i}^{\text {equ }}}\right)$ obtained for each studied sample using the kinetic approach were compared to the same parameters obtained using the at-equilibrium approach. Results showed a good agreement between both techniques (Fig. 5). It could be noticed that almost all "kinetic" stability constant are higher for about 0.2 logarithm units (Fig. 5B). We suppose that this small deviation could arise from uncertainty in $\mathrm{Cu}_{\text {labile }}$ (at $0 \mathrm{~s}$ ) estimation and/or from insufficient waiting time in the at-equilibrium approach.

Although leading to similar results, these two approaches of data fitting should be considered as complementary. By fitting experimental data, the at-equilibrium approach allows averaging uncertainty due to analysis errors and as the comprised range of metal/ligand ratio is more important, it leads to a better estimation of the ligands concentration. However, this approach supposes that after each addition a new pseudo-equilibrium is reached. The kinetic approach treats all the data points after each addition, and allows determining for each class of ligands not only the stability constant $K_{i}^{\text {equ }}$ but its association $\left(k_{i}^{1}\right)$ and dissociation $\left(k_{i}^{-1}\right)$ rate constants. Still, one should be aware that there are obstacles such as (i) uncertainty in the estimation of the labile copper concentration at $0 \mathrm{~s}$ of equilibration time, (ii) most of the curves (all except for the few last copper additions) are fitted under conditions of non-saturated ligands, and (iii) at the lowest total copper concentrations, when the curvature of the labile copper concentration versus the equilibration time is well defined, the measured labile copper concentrations are close to the detection limit of the DPASV method, and so quite noise affected.

3.2.1. Variation of association/dissociation constants and their application in the prediction of dynamics of copper complexation by DNOM

The association constants values obtained for both campaigns were systematically higher for the strong class of ligands ( $\log \mathrm{k}_{1}^{1}$ average value of 4.1) compared to the weak class (average value of 3.5) (Table 1). Variation of the dissociation constants was bigger $\left(\log k_{1}^{-1}\right.$ and $\log k_{2}^{-1}$ average values of -8.2 and -6.1 , respectively). The range of obtained association/dissociation constants values is comparable to those from the literature, even if there are scarce and rarely concern DNOM. 

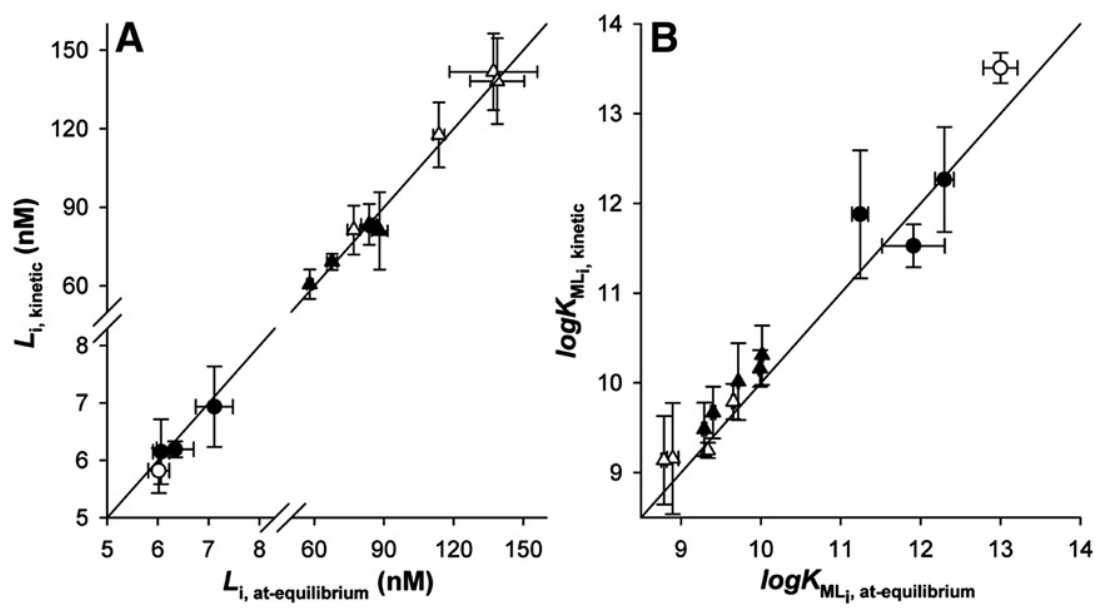

Fig. 5. Comparison of the complexing parameters (A-ligands concentrations and B-stability constant) obtained by the kinetic and the at-equilibrium approaches for samples taken in $2007(\circ, \triangle)$ and $2008(\bullet, \mathbf{\Lambda})$. Parameters obtained for strong $(\circ, \bullet)$ and weak $(\triangle, \mathbf{\Lambda})$ complexes.

Raspor et al. (1980) observed a strong decrease of EDTA association rate toward different trace metals with increasing divalent cations concentrations, and pointed out the major role of calcium. The slow association rate of the ligands analysed in our study could be equally linked to a competition between copper and major divalent cations vs. the DNOM binding sites. Indeed, DNOM complexation with copper needs a preliminary dissociation of DNOM complexes with major cations, which could be slow (Hering and Morel, 1989). Raspor et al. (1980) have calculated $k_{1}$ values $v s$. Pb in different seawater samples ranging from 3.2 to 3.6. Taking into account that $\mathrm{Cu}$ is known to form stronger complexes with EDTA than $\mathrm{Pb}$, its association constants should be slightly higher. Ligands analysed in our study showed association constants in the same range of values, even if the transposition of constants from different ligands with different trace metals is not obvious (although it is the assumption of the linear free energy relationship (LFER) (Hirose, 2006)).

Hering and Morel (1989), studying salinity influence on copper complexation by a mixture of EDTA and extracted humic substances, have supposed that copper association rate with extracted NOM should not be modified, and have calculated that association rate of the model strong ligand with copper should have decreased due to highest competition effect of divalent cations. But they followed the complexation of extracted NOM using fluorescence quenching technique, which is less sensitive and selective than DPASV, and with higher copper and DOC concentrations than in our study.

Ma et al. (1999) have studied the kinetic of copper association with extracted humic acid in presence of calcium. According to the equation describing the kinetic copper complexation with ligands (see Eq. (5)), they defined association constants as, $k_{\mathrm{i}}^{*}=k_{\mathrm{i}}^{1} \times L_{i}$ assuming that $L_{i}$ corresponds to the total concentration of ligand $\left(L_{i T}\right)$ and not the free one, which dramatically simplifies the fitting procedure. Applying our program and using their values obtained for the strongest ligand concentration $\left(L_{i T}\right)$ and association rate $\left(k_{\mathrm{i}}^{*}\right)$, the log of corresponding association constant could be estimated to 3.2. Despite different analytical conditions (artificial sample, higher total copper and humic acid contents, potentiometric detection), this value is of the same order as those obtained in our study.

The dissociation constants obtained for the weak ligands $\left(\log \mathrm{k}_{2}^{-}\right.$ ${ }^{1}$ average value of -6.1 ) were lower than the value of -5 obtained by Fasfous et al. (2004) for a model solution of Laurentian river fulvic acid. This difference could partly be explained by their different analytical conditions: $\mathrm{pH} 5$ and a low ionic strength $(6 \mu \mathrm{M})$.

The strong ligand noticeable for the 2008 samples indicated a very slow dissociation constant $\left(\log k_{1}^{-1}\right)$ of -8 , showing the importance of strong complexing sites which were able to strongly complex copper and so can easily dominate metal speciation in the environment.

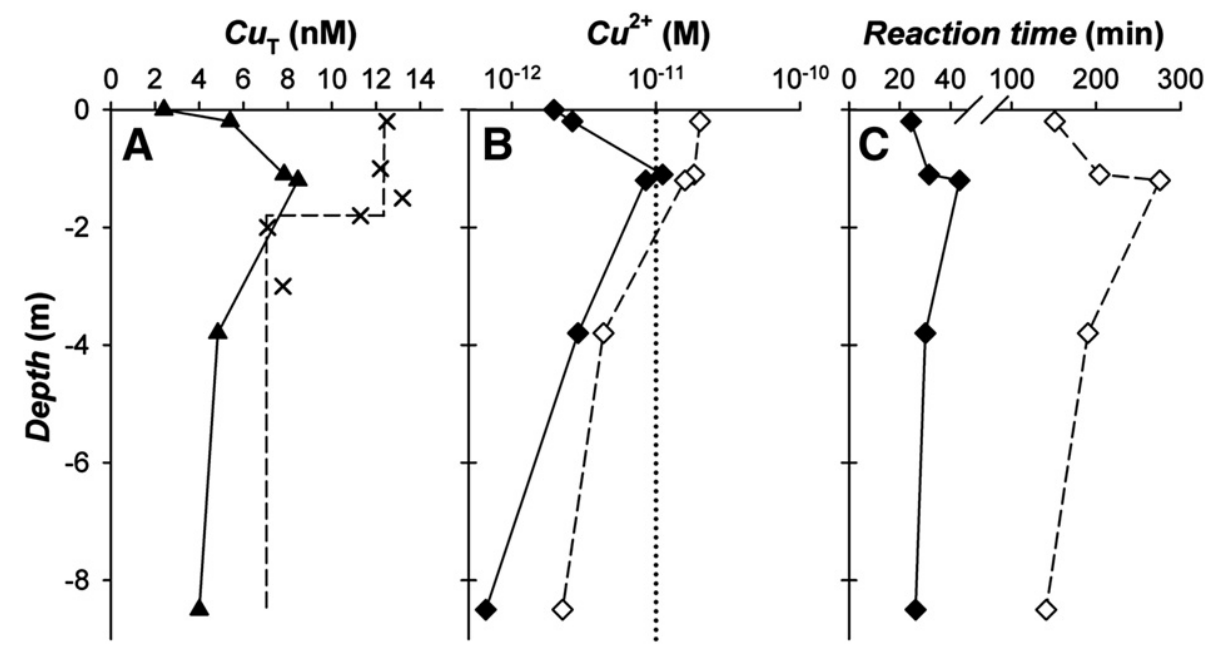

Fig. 6. (A)-comparison of total copper concentration profiles for 2008 ( $\mathbf{\Delta}$ ) and those obtained by Omanović et al. (2006) (X). Dashed line represents projection of total copper concentration profile (see text for details). (B)-corresponding free copper concentration for $2008(\diamond)$ and for the projected profile $(\diamond)$; dotted line represents toxicity limit (see text). (C)-reaction time of organically complexed Cu (calculations according to the projected profile),-kinetics for $50 \%(\diamond)$, and for $99 \%(\diamond)$. 
From these data, it can be deduced that the main difference in DNOM reactivity for strong ligands was mainly due to their very small dissociation constants. Generally, the small increase of association constants coupled with a decrease of the dissociation ones explained the higher stability constants $\left(K_{i}^{\text {equ }}\right)$ found in samples of higher salinity.

These experiments gave us important additional information on DNOM reactivity in natural system. The obtained data are essential for ecosystems that are periodically or often under dynamic conditions where new equilibration processes can significantly change metal speciation.

According to Cukrov et al. (2008), the Krka River has a small input of copper to the estuary along the year. However, Omanovic et al. (2006) observed increased copper concentration in the surface layer during the summer, probably due to traffic of tourist's boats, with total copper concentrations higher than $12 \mathrm{nM}$ (Fig. 6A, crosses). Our results from 2008 are given for comparison (Fig. 6A, triangles). A simplified simulated total copper concentration depth profile (Fig. 6A, dashed line) was defined in order to trace response of the copper speciation induced by its increased content. For the simulated increased copper concentration, the calculated free copper contents for each depth in the upper layer overpassed the toxicity limit of $10 \mathrm{pM}$ defined by Sunda et al. (1987), contrary to our values obtained in the 2008 samples (Fig. 6B open diamonds and diamonds, respectively).

To predict the dynamics of copper complexation in the water column of the Krka River estuary, dependences of $\mathrm{Cu}_{\text {labile }}$ concentrations versus equilibration time (from 0 to $500 \mathrm{~min}$ ) were calculated for the given depth profile of total copper concentrations (data not shown). From the obtained curves, time for $50 \%\left(t^{50}\right)$ and for $99 \%\left(t^{99}\right)$ of copper complexation was determined (Fig. 6C). The fastest achievement of a new equilibrium initiated by copper additions was observed for surface and sea water samples. Half of the total metal complexation was accomplished in $25 \mathrm{~min}$ and the pseudo-equilibrium was reached in $2 \mathrm{~h} 30 \mathrm{~min}\left(t^{99}\right)$. In the FSI layer, longer time was needed, with $t^{99}$ values reaching $4 \mathrm{~h} 30 \mathrm{~min}$. The sample at salinity 31 (depth $-1.2 \mathrm{~m}$ ) compared to the sample at salinity 19 (depth $-1.1 \mathrm{~m}$ ) showed slightly lower free copper concentrations but considerably longer equilibration times (Fig. 6B and C). The difference in free copper concentration is attributed to the presence of an additional stronger ligand $\left(L_{1}\right)$ at the point of salinity 31 (see Fig. 4A and B), not present at the point of salinity 19 . The difference in equilibration time is attributed to slower association rates (see Table 1).

Taking into account the hydrodynamic variations expected in such an estuary, these long equilibrium times are not negligible and indicate that the studied system is often not at equilibrium, particularly at the mixing interface between fresh and sea waters, where major biogeochemical processes occur.

\section{Conclusion}

Two comparative approaches were used to study copper-dissolved natural organic matter (DNOM) interaction in the water column of the stratified Krka River estuary: (i) an at-equilibrium and (ii) a kinetic approach. Both approaches are based on the measurement of labile copper complexes at increasing total copper concentration by DPASV.

Obtained results revealed non-conservative behaviour of total dissolved copper and DOC distribution along the salinity gradient. Owing to the software developed for the fitting of experimental data for both at-equilibrium and kinetic model, one or two discrete classes of natural ligands forming inert copper complexes were resolved. For the surface brackish layer, copper complexation is characterized by only one class of ligands with relatively low concentration ( $16.3 \mathrm{nM})$ and quite high apparent stability constant $\left(\log K_{1}^{\text {equ }}=10.9\right)$, while for most of the other samples, two classes of binding ligands were distinguished ( $\left.\log K_{1}^{\text {equ }}: 11.2-13.0, \log K_{2}^{\text {equ }}: 8.8-10.0\right)$. An increase of apparent stability constants with the salinity indicated stronger interaction of copper with autochthonous ligands produced in-situ as a result of biological activity.

Although a kinetic approach is not common in the determination of metal complexation parameters, our results validated its applicability and reliability in the determination of apparent stability constants and ligand concentrations. In addition, the kinetic model provided a calculation of the association/dissociation rate constants, allowing evaluation of the dynamic properties of copper complexation. Relatively slow formation rates of copper complexation $\left(k_{1}^{1}: 6.1-\right.$ $20 \times 10^{3}\left(\mathrm{M} \mathrm{s}^{-1}, k_{2}^{1}: 1.3-6.3 \times 10^{3}\left(\mathrm{M} \mathrm{s}^{-1}\right)\right.$ indicate that in the water column of the Krka River estuary, an achievement of the pseudoequilibrium (99\%) of copper complexation (induced by copper concentration increase) could last up to $4 \mathrm{~h} 30 \mathrm{~min}$.

In spite of the fact that the Krka River estuary is considered as nonpolluted, an increase of the copper concentration in surface water layers above $10 \mathrm{nM}$ (as a consequence of the copper dissolution from the anti-fouling boats coatings) could take place during summer season. Taking into account very low DOC content, it is estimated that the concentration of toxic copper specie (free ion, $\mathrm{Cu}^{2+}$ ) could surpass the toxic threshold level $\left(10^{-11} \mathrm{M}\right)$. Considering slow kinetics of copper complexation, this toxic concentration could be even higher than its equilibrium value.

Obtained results confirmed that in water systems subjected to fast and frequent physico-chemical perturbations, metal speciation is often not at equilibrium. Thus, the dynamic properties of metal complexation should be provided in addition to the metal speciation data predicted by numerical models, which assume equilibrium conditions.

In order to better describe, understand and be able to predict the copper behaviour and cycling at the very location of the Krka River estuary, more frequent samplings at characteristic points of this stratified estuary are envisaged and other are in course.

\section{Acknowledgements}

The authors wish to thank the French research group MONALISA (convention number: $\mathrm{n}^{\circ} 03 / 1214910 / \mathrm{T}$ ) supported by the IFREMER institute, the French Ministry of Education and Research, ProvenceAlpes-Côte d'Azur regional council and the Ministry of Science, Education and Sports of the Republic of Croatia (through Grant No. 098-0982934-2720) for Y. L. Ph.D. support and funding.

\section{References}

Achterberg, E.P., Van Elteren, J.T., Kolar, Z.I., 2002. Species kinetics and heterogeneous reactivity of dissolved $\mathrm{Cu}$ in natural freshwaters. Environ. Sci. Technol. 36, 914-920.

Ahel, M., Barlow, R.G., Mantoura, R.F.C., 1996. Effect of salinity gradients on the distribution of phytoplankton pigments in a stratified estuary. Mar. Ecol. Prog. Ser 143, 289-295.

Baeyens, W., Parmentier, K., Goeyens, L., Ducastel, G., De Gieter, M., leermakers, M., 1997. The biogeochemical behaviour of $\mathrm{Cd}, \mathrm{Cu}, \mathrm{Pb}$ and $\mathrm{Zn}$ in the Scheldt estuary: results of the 1995 surveys. Hydrobiologia 366, 45-62.

Benedetti, M.F., 2006. Metal ion binding to colloids from database to field system. J. Geochem. Explor. 88, 81-85.

Bonacci, O., Jukić, D., Ljubenkov, I., 2006. Definition of catchment area in karst: case of the river Krčić and Krka, Croatia. Hydrol. Sci. J. 51, 682-699.

Bruland, K.W., Lohan, M.C., 2004. Controls of trace metals in seawater. In: Holland, H.D., Turekian, K.K. (Eds.), Treatise on geochemistry, vol 6. Elsevier Pergamon, pp. 23-47.

Buffle, J. 1988. Complexation reaction in Aquatic Systems-analytical approach, Ellis Hortwood series Limited in analytical chemistry, Chichester, England. ISBN: 0 85312557 0, p. 692.

Buffle, J., Tercier-Waeber, M.-L., 2005. Voltammetric environmental trace metal analysis and speciation: from laboratory to in situ measurements. Trends Anal. Chem. 24, 172-191.

Capodaglio, G., Scarponi, G., Toscano, G., Barbante, C., Cescon, P., 1995. Speciation of trace metals in seawater by anodic stripping voltammetry: critical analytical steps. Fresenius J. Anal. Chem. 351, 386-392.

Cauwet, G., 1991. Carbon inputs and biogeochemical processes at the halocline in a stratified estuary: Krka River, Yugoslavia. Mar. Chem. 32, 269-283.

Cheng, T., Allen, H.E., 2006. Comparison of zinc complexation properties of dissolved natural organic matter from different surface waters. J. Environ. Manage. 80, $222-229$ 
Coale, K.H., Bruland, K.W., 1988. Copper complexation in the Northeast Pacific. Limnol. Oceanogr. 33, 1084-1101.

Cukrov, N., Cmuk, P., Mlakar, M., Omanović, D., 2008. Spatial distribution of trace metals in the Krka River, Croatia: an example of the self-purification. Chemosphere 72, 1559-1566.

Dudal, Y., Gerard, F., 2004. Accounting for natural organic matter in aqueous chemical equilibrium models: a review of the theories and applications. Earth-Sci. Rev. 66, 199-216.

Dzombak, D.A., Fish, W., Morel, F.M.M., 1986. Metal-Humate interactions: 1 Discrete ligand and continuous distribution models. Environ. Sci. Technol. 20, 669-675.

Elbaz-Poulichet, F., Guan, D.M., Martin, J.-M., 1991. Trace metal behaviour in a highly stratified Mediterranean estuary: the Krka (Yugoslavia). Mar. Chem. 32, 211-224.

Fasfous, I.I., Yapici, T., Murimboh, J., Hassan, N.M., Chakrabarti, C.L., Back, M.H., Lean, D.R.S., Grégoire, D.C., 2004. Kinetics of trace metal competition in the freshwater environment: some fundamental characteristics. Environ. Sci. Technol. 38, 4979-4986.

Garnier, C., Mounier, S., Benaïm, J.-Y., 2004a. Metal logarithmic scale titration as a tool for complexing ligand distribution determination: an application by DPASV. Environ. Technol. 25, 589-599.

Garnier, C., Pižeta, I., Mounier, S., Benaïm, J.-Y., Branica, M., 2004b. Influence of the type of titration and of data treatment methods on metal complexing parameters determination of single- and multi-ligand systems measured by stripping voltammetry. Anal. Chim. Acta 505, 263-275.

Garnier, C., Pižeta, I., Mounier, S., Cuculić, V., Benaïm, J.-Y., 2005. An analysis of distinguishing composite dissolved metal-ligand systems measurable by stripping voltammetry. Anal. Chim. Acta 538, 263-271.

Hamilton-Taylor, J., Postill, A.S., Tipping, E., Harper, M.P., 2002. Laboratory measurements and modeling of metal-humic interactions under estuarine conditions. Geochim. Cosmochim. Acta 66, 403-415.

Hassan, N., Murimboh, J.D., Chakrabarti, C.L., 2008. Kinetic speciation of $\mathrm{Ni}(\mathrm{II})$ in model solutions and freshwaters: competition of $\mathrm{Al}(\mathrm{III})$ and $\mathrm{Fe}(\mathrm{III})$. Water Air Soil Pollut. 193, 131-146.

Herbelin, A.L., Westall, J.C., 1999. FITEQL 4.0: A Computer Program for Determination of Chemical Equilibrium Constants from Experimental Data. Department of Chemistry, Oregon State University. Report 99-01, Corvallis.

Hering, J.G., Morel, F.M.M., 1988. Kinetics of trace metal complexation: role of alkalineearth metals. Environ. Sci. Technol. 22, 1469-1478.

Hering, J.G., Morel, F.M.M., 1989. Slow coordination reactions in seawater. Geochim. Cosmochim. Acta 53, 611-618.

Hering, J.G., Morel, F.M.M., 1990. Kinetics of trace metal complexation: ligand-exchange reactions. Environ. Sci. Technol. 24, 242-252.

Hirose, K., 2006. Chemical speciation of trace metals in seawater: a review. Anal. Sci. 22, $1055-1063$.

Hirose, K., 2007. Metal-organic matter interaction: ecological roles of ligands in oceanic DOM. Appl. Geochem. 22, 1636-1645.

Huber, C., Filella, M., Town, R.M., 2002. Computer modelling of trace metal ion speciation: practical implementation of a linear continuous function for complexation by natural organic matter. Comput. Geosci. 28, 587-596.

Kinniburgh, D.G., Milne, C.J., Benedetti, M.F., Pinheiro, J.P., Filius, J., Koopal, L.K., Van Riemsdijk, W.H., 1996. Metal ion binding by humic acid: application of the NICADonnan Model. Environ. Sci. Technol. 30, 1687-1698.

Langford, C.H., Cook, R.L., 1995. Kinetic versus equilibrium studies for the speciation of metal complexes with ligands from soil and water. Analyst 120, 591-596.

Lenoble, V., Garnier, C., Masion, A., Ziarelli, F., Garnier, J.M., 2008. Combination of 13C/ $113 \mathrm{Cd}$ NMR, potentiometry, and voltammetry in characterizing the interactions between $\mathrm{Cd}$ and two models of the main components of soil organic matter. Anal. Bioanal. Chem. 390, 749-757.

Louis, Y., Cmuk, P., Omanović, D., Garnier, C., Lenoble, V., Mounier, S., Pižeta, I., 2008. Speciation of trace metals in natural waters: the influence of an adsorbed layer of natural organic matter (NOM) on voltammetric behaviour of copper. Anal. Chim. Acta 606, 37-44.

Louis, Y., Garnier, C., Lenoble, V., Omanović, D., Mounier, S., Pižeta, I., 2009. Characterisation and modelling of marine dissolved organic matter interactions with major and trace cations. Mar. Environ. Res. 67, 100-107.

Lu, Y., Allen, H.E., 2002. Characterization of copper complexation with natural dissolved organic matter (DOM)-link to acidic moieties of DOM and competition by Ca and Mg. Water Res. 36, 5083-5101.
Ma, H., Kim, S.D., Cha, D.K., Allen, H.E., 1999. Effect of kinetics of complexation by humic acid on toxicity of copper to Ceriodaphnia dubia. Environ. Toxicol. Chem. 18, 828-837.

McKnight, D.M., Morel, F.M.M., 1979. Release of weak and strong copper-complexing agents by algae. Limnol. Oceanogr. 24, 823-837.

Muller, F.L.L., Gulin, S.B., Kalvøy, Å., 2001. Chemical speciation of copper and zinc in surface waters of the western Black Sea. Mar. Chem. 76, 233-251.

Omanović, D., Kwokal, Ž., Goodwin, A., Lawrence, A., Banks, C.E., Compton, R.G., Komorsky-Lovrić, Š., 2006. Trace metal detection in Šibenik bay, Croatia: Cadmium, lead and copper with anodic stripping voltammetry and manganese via sonoelectrochemistry. A case Study, J. Iranian Chem. Soc. 3, 128-139.

Plavšić, M., Kwokal, Ž., Strmečki, S., Peharec, Ž., Omanović, D., Branica, M., 2009. Determination of the copper complexing ligands in the Krka river estuary. Fresenius Environ. Bull. 18, 327-334.

Raspor, B., Nürnberg, H.W., Vanlenta, P., Branica, M., 1980. Kinetics and mechanism of trace metal chelation in sea water, presented in part at the Vth International Symposium, Chemistry of the Mediterranean, Rovinj, 8th-12th May, 1978. J. Electroanal. Chem. 115, 293-308.

Ružić, I., 1982. Theoretical aspects of the direct titration of natural waters and its information yield for trace metal speciation. Anal. Chim. Acta 140, 99-113.

Scatchard, G., 1949. The attraction of proteins for small molecules and ions. Ann. N.Y. Acad. Sci. 51, 660-672.

Shank, G.C., Skrabal, S.A., Whitehead, R.F., Kieber, R.J., 2004. Strong copper complexation in an organic-rich estuary: the importance of allochthonous dissolved organic matter. Mar. Chem. 88, 21-39.

Sposito, G., 1981. Trace metals in contaminated waters. Environ. Sci. Technol. 15, 396-403.

Sunda, W.G., Tester, P.A., Huntsman, S.A., 1987. Effects of cupric and zinc ion activities on the survival and reproduction of marine copepods. Mar. Biol. 94, 203-210.

Svensen, C., Viličić, D., Wassmann, P., Arashkevich, E., Ratkova, T., 2006. Plankton distribution and vertical flux of biogenic matter during high summer stratification in the Krka estuary (Eastern Adriatic). Estuar. Coast. Shelf Sci. 71, 381-390.

Tercier-Waeber, M.-L., Confalonieri, F., Riccardi, G., Sina, A., Noel, S., Buffle, J., Graziottin, F., 2005. Multi physical-chemical profiler for real-time in situ monitoring of trace metal speciation and master variables: development, validation and field applications. Mar. Chem. 97, 216-235

Tipping, E., Lofts, S., Lawlor, A.J., 1998. Modelling the chemical speciation of trace metals in the surface waters of the Humber system. Sci. Total Environ. 210-211, 63-77.

Town, R.M., Filella, M., 2000. Dispelling the myths: is the existence of L1 and L2 ligands necessary to explain metal ion speciation in natural waters? Limnol. Oceanogr. 45 , 1341-1357.

Van der Lee, J., De Windt, L., 2000. CHESS Tutorial and Cookbook. User's Guide Nr. LHM/ RD/99/05, CIG-École des Mines de Paris, Fontainebleau, France.

Vetter, T.A., Perdue, E.M., Ingall, E., Koprivnjak, J.-F., Pfromm, P.H., 2007. Combining reverse osmosis and electrodialysis for more complete recovery of dissolved organic matter from seawater. Separ. Purif. Technol. 56, 383-387.

Waeles, M., Riso, R.D., Maguer, J.-F., Le Corre, P., 2004. Distribution and chemical speciation of dissolved cadmium and copper in the Loire estuary and North Biscay continental shelf, France. Est. Coast. Shelf Sci. 59, 49-57.

Waeles, M., Riso, R.D., Le Corre, P., 2005. Seasonal variations of dissolved and particulate copper species in estuarine waters. Est. Coast. Shelf Sci. 62, 313-323.

Wang, R., Chakrabarti, C.L., 2008. Copper speciation by competing ligand exchange method using differential pulse anodic stripping voltammetry with ethylenediaminetetraacetic acid (EDTA) as competing ligand. Anal. Chim. Acta 614, 153-160.

Wells, M.L., Kozelka, P.B., Bruland, K.W., 1998. The complexation of "dissolved" Cu, Zn, $\mathrm{Cd}$ and $\mathrm{Pb}$ by soluble and colloidal matter in Narragansett Bay, RI. Mar. Chem. 62 , 203-217.

Westall, J.C., Zachary, J.L., Morel, F.M.M., 1976. MINEQL, a computer program for the calculation of chemical equilibrium composition of aqueous systems. R.M. parsons laboratory technical note 18. Massachusetts institute of technology, Cambridge MA.

Žutić, V., Legović, T., 1987. A film of organic matter at the fresh-water/sea-water interface of an estuary. Nature 328, 612-614. 